\title{
As redes sociotecnológicas e a operação do imaginário instituinte
}

\author{
Angela Pintor dos Reis \\ I- SENAC \\ São Paulo (SP), Brasil
}

Resumo: O estudo discute as maneiras pelas quais as redes sociotecnológicas expressam a conjugação de legein e de teukhein, conforme esses termos são concebidos por Castoriadis para designar dimensões do imaginário instituinte. Trata-se de uma reflexão teórica desenvolvida com o objetivo de qualificar as referidas redes como processos do imaginário social. A relevância da discussão reside no tratamento epistemológico inusual das redes sociotecnológicas, abordadas como elementos constituintes dos processos de criação e instituição do social. O procedimento metodológico consistiu na interpretação dos conceitos de legein e de teukhein, aplicados a configurações da comunicação tecnológica mediática, engendrada pelo imaginário de época. O resultado traduziu-se na caracterização das redes sociotecnológicas como expressões do imaginário atinente ao terceiro espírito do capitalismo, segundo perspectiva de Boltanski e Chiapello.

Palavras-chave: redes sociotecnológicas; legein; teukhein; imaginário instituinte.

Abstract: Sociotechnological networks and institutive imaginary operation - This paper discusses the ways in which sociotechnological networks express the conjugation of legein and teukhein, as these terms are conceived by Cornelius Castoriadis, to denote dimensions of institutive imaginary. This is a theoretical reflection aimed at qualifying the aforementioned networks as processes of the social imaginary. The relevance of this discussion lies in the unusual epistemological treatment of sociotechnological networks, which are addressed as constituent elements of the processes of social creation and institution. The methodological procedure consisted in the interpretation of the concepts of legein and teukhein, applied to the configurations of mediatic technological communication, engendered by the the imaginary of the times. The result is the characterization of sociotechnological networks as expressions of imaginary pertaining to the third spirit of capitalism, according to Boltanski and Chiapello.

Keywords: sociotechnological networks; legein; teukhein; institutive imaginary. 
No percurso de sua crítica à concepção materialista da história, advinda de Marx e multiplicada por sistemas de pensamento desenvolvidos na tradição marxista, Castoriadis (1982) elaborou uma teoria sobre o imaginário na qual equiparou esse termo a um processo de criação ex nihilo, devir que confere existência a variedades de formas figuras, instrumentos técnicos, linguagem e imagens, das mentais aos objetos visuais (CASTORIADIS, 1982, p. 13).

Castoriadis (1982, p. 41) igualou o materialismo histórico a uma ideologia que, segundo ele, sustentava-se em três pilares: considerava a técnica elemento autônomo e protagonista da história em última instância; compreendia a história a partir de princípios e dinâmicas exclusivas do modo capitalista de produção e da luta de classes; e pressupunha que a natureza humana era inalterável e motivada, eminentemente, pela razão econômica. Em síntese, para Castoriadis, a concepção materialista da história esteve, ao longo do tempo, carregada de determinismo econômico e, em decorrência desse posicionamento, ignorou a relação inevitável entre psique e sociedade, necessária para a criação ex nihilo de significações, empenhadas com a instituição imaginária do indivíduo e da sociedade.

A posição crítica de Castoriadis em relação à concepção marxista da história situa-se no percurso intelectual desenvolvido pelo autor em defesa da autonomia como modo de ser do sujeito e da sociedade. A autonomia é termo-chave em sua obra, correspondendo à prática de se colocar em questão as leis na qualidade de significações instituídas para a conservação heteronômica de indivíduos e da sociedade (CASTORIADIS, 1983, p. 11 34). A capacidade do sujeito e da sociedade de se autoinstituirem, criando suas próprias leis, corresponde ao trabalho do imaginário de pôr em forma socializada o que não havia antes. A questão da autonomia está, portanto, atada à interrogação sobre o que pode o imaginário como ato de criação de sentido, e à necessidade de a psique sair de seu fechamento (CASTORIADIS, 1999, p. 36-37). ${ }^{1}$

As significações imaginárias às quais Castoriadis se refere (2006, p. 65-66) são o que confere coesão à sociedade e mantém os indivíduos juntos, colaborando para a formação de um tecido comum de sentido. Por isso, para o autor, não seria possível atribuir ao imaginário um papel secundário, menor ou dissociado da dimensão econômica da sociedade. Este teria sido o equívoco do materialismo histórico: distinguir o racional e o imaginário, atribuindo a este último uma função limitada em relação ao econômico (CASTORIADIS, 1982, p. 158-160).

Como afirma Castoriadis (1982, p. 260-313), as significações imaginárias processam-se por meio de dois conjuntos de atividades - o legein e o teukhein - que asseguram organização ao imaginário no processo de criação ex nihilo instituinte do social-histórico. O legein corresponde às operações de distinguir, escolher, estabelecer, juntar, contar e dizer, assentadas em linguagem. O teukhein designa o juntar, ajustar, fabricar e construir

1 A partir das relações entre autonomia, imaginário e psique Castoriadis desenvolveu um trabalho intelectual interdisciplinar, situado na intersecção entre psicanálise, filosofia e sociologia, advindo de sua própria formação como filósofo, economista e psicanalista. 
que representam o fazer social. Esses grupos de atividades são ordenadores da vida em sociedade e das formas de sentido que ela produz para sua própria existência e conservação. São dimensões mutuamente implicadas e operam orientadas por uma lógica identitária-conjuntista, isto é, por uma maneira de combinar e criar equivalências entre formas e significações socialmente instituídas. ${ }^{2}$

A consideração desses fundamentos estimula a reflexão sobre o modo como podem ser interpretadas as relações, intrincadas e inelidíveis, entre sociedade, tecnologia e comunicação mediática, na medida em que esses três termos correspondem a criações do imaginário instituinte. Mais especificamente, na atualidade, essas criações constituem o contexto no qual as redes sociotecnológicas sobressaem-se como expressões da articulação entre legein e teukhein, tendo aquelas se transformado em realidade institucionalizada. Tais redes são nomeadas dessa maneira (sociotecnológicas) com duas intenções. Primeiro, para suavizar o pleonasmo que constitui o termo "redes sociais"; segundo, para atribuir ao significante linguístico uma função representativa da condição social da técnica/tecnologia. Mesmo com esse esforço de precisão, não é possível eliminar totalmente a redundância contida no termo, a se considerar que a técnica/tecnologia é, ela mesma, expressão da socialização de formas ou de representações criadas pela psique, como será visto adiante.

O entendimento sobre o que é o social, portanto, distancia-se de uma abordagem que exclui a psique e o inconsciente dos processos de criação e reelaboração de sentido, próprios do psiquismo humano. Nesse contexto, o social corresponde às significações imaginárias socializadas, sancionadas nas relações entre indivíduos, e incorporadas no hábito, no gosto, na moral, na cultura, na linguagem, nos objetos, nas normas, nas práticas profissionais, nos media, nos discursos sobre o outro e o mundo, nas instituições etc. Essas significações imaginárias podem ser funcionais ou disfuncionais, neste último caso porque tanto o inconsciente quanto a psique ignoram a contradição e a ambivalência, criando representações de prazer sublimadas, que superam ou são independentes do prazer de órgão (CASTORIADIS, 1999, p. 35-36).

Motivado por essa conjuntura, este estudo dedica-se à compreensão das relações entre imaginário instituinte, legein, teukhein e redes sociotecnológicas, com o propósito de contribuir para o debate sobre a interdependência entre formas de sociabilidade mediatizada (elaboradas na relação entre subjetividade, media e tecnologia) ${ }^{3}$, especificamente aquelas pertinentes à configuração das redes sociotecnológicas,

2 Embora sejam operações do imaginário, o legein e o teukhein não o totalizam. Sendo criação ex nihilo, o imaginário está vinculado às criações psíquicas, nem sempre compatíveis com a lógica identitária-conjuntista (KLOOGER, 2014, p. 112-113). Elaboradas pela imaginação radical, assemelhada ao trabalho da psique como formante do imaginário, essas criações não são necessariamente coerentes com as significações instituídas pelo social-histórico (CASTORIADIS, 1982, p. 316-323).

3 A sociabilidade é codeterminada no encontro das propriedades da subjetividade (imaginação, fantasias, desejos, pulsões, sentimentos) com as formas (imaginário transposto em narrativas e funcionalidades) dos media de massa e interativos. 
e o imaginário instituinte. Como será visto adiante, a articulação e nomeação dessas redes são a própria expressão do modo como opera esse imaginário. Em última instância, pretende-se qualificar as referidas redes como processos de criação e instituição do social-histórico de época. Em razão do interesse teórico deste estudo, a reflexão parte dos conceitos-chave acima especificados para relacioná-los às condições de formação dos media e, em particular, das referidas redes, com a intenção de assentar conceitos em elementos concretos da comunicação mediática na atualidade, com ênfase em processos presididos pela sociabilidade tecnológica.

Embora o pensamento de Castoriadis sobre o imaginário não corresponda a uma teoria da comunicação, nem esteja filiado a ou tenha inspirado teorias propriamente ditas de comunicação, ele é assumido neste estudo como fundamento prioritário para se compreender um fenômeno comunicacional, típico da fase avançada do capitalismo mediático-tecnológico. A principal razão para essa decisão está no fato de a obra do autor permitir a inclusão da psique como dimensão necessária e atuante na criação de processos mediáticos e dos próprios media, possibilitando a identificação de continuidades entre imaginário/psique e sociedade. Esse caminho interpretativo oferece condições para se evitar a polarização entre media e sociedade e para acolher a imaginação como ato de criação de formas, livrando-a de vínculos históricos com a fantasia e com um suposto não real. Em certa medida, a teoria do imaginário de Castoriadis pode dialogar, sempre a depender da tradição ou ideologia de um autor, com teorias críticas da comunicação, especificamente dedicadas ao signo, à imagem e ao simbólico, e às relações de dependência entre comunicação, técnica/tecnologia, corpo e sociedade. Lato sensu, a teoria do imaginário em questão colabora para interpretações das próprias teorias da comunicação, uma vez que estas são criações e se dedicam a outras tantas criações na função de objetos de estudo.

\section{O imaginário, o legein e o teukhein}

O imaginário de que trata Castoriadis é tanto potência quanto ato de criação de formas que, sendo socializadas e institucionalizadas, traduzem a vigência do imaginário social instituinte (formante) e qualificam o imaginário social instituído (magma de representações). O engendramento ex nihilo de formas (CASTORIADIS, 2004, p. 129) tem natureza ontológica, envolvendo a capacidade humana de criar, de maneira radical, configurações, condensadas, grosso modo, em linguagem, arte, ciência, técnica e em variedades de instituições. Estas últimas são redes simbólicas, socialmente sancionadas, que se organizam por meio de relações entre componentes funcionais e imaginários (CASTORIADIS, 1982, p. 159). Tais relações, embora determinem sentidos para objetos, práticas e comportamentos, também são constituídas por brechas e por graus de liberdade que possibilitam variações, alargamentos e deslocamentos de significações (CASTORIADIS, 1982, p. 152-155). Embora o imaginário seja a condição necessária para que o simbólico 
seja criado e reproduzido como tecido social de sentido, ele não se restringe ao que é simbolicamente constituído por uma sociedade. O imaginário radical usa o simbólico para se expressar, porém, além disso, elabora formas nem sempre expressas por meio do simbólico instituído, como é o caso da criação de cenas e de formas pela psique em sua atividade, incessante e incontrolável, de elaboração de si para si mesma.

Há, portanto, uma interdependência entre imaginário radical e imaginário social. O primeiro é assemelhado à psique, propriedade dos seres humanos existente como emergência e fluxo ininterrupto de formas, representações e significações (CASTORIADIS, 1982, p. 154). Já o imaginário social elabora-se na coagulação de significações formalizadas, aceitas e reproduzidas na vida social durante a socialização da psique. Esta socialização é fundamental para que haja certa organização das formas psíquicas, de maneira que uma sociedade consiga produzir realidades ordenadas, estáveis e minimente duradouras, em relação às quais os indivíduos se posicionam. Segundo Castoriadis (2004, p. 131-132), se os seres humanos estivessem entregues ao imaginário radical, eles não conseguiriam sobreviver porque, assimilado à psique, e esta sendo fluxo contínuo de formas sem correspondência necessariamente lógica, não seria possível a realidade social instituída. Como explica Castoriadis (2004, p. 132, grifo do autor),

\begin{abstract}
É preciso, portanto, que essa imaginação radical dos seres humanos seja domada, canalizada, regulada, adequando-se à vida em sociedade e também ao que chamamos de "realidade". Isso se faz por intermédio de sua socialização, durante a qual eles absorvem a instituição da sociedade e suas significações, interiorizamnas, aprendem a linguagem, a categorização das coisas, o que é justo e injusto, o que se pode fazer e o que não se deve fazer, o que se deve adorar e o que se deve odiar. Quando essa socialização se realiza, a imaginação radical é, até um certo ponto, sufocada em suas manifestações mais importantes, sua expressão se torna conforme e repetitiva.
\end{abstract}

O imaginário social é, desse modo, uma formação institucionalizada e necessária, não apenas para a elaboração de significações, mas também para o assentamento do imaginário radical e para a estabilização de formas, representações e significações, sem o que uma sociedade não poderia formar-se e perdurar. Em síntese, as significações imaginárias sociais (ou socializadas) condensam-se em instituições que são representações criadas no e pelo imaginário social instituído, cuja função é assegurar a formação e a conservação da sociedade (CASTORIADIS, 2004, p. 130).

As capacidades e formas de ação humanas comprometidas com esse ordenamento do social são, segundo Castoriadis (1982, p. 259-313), o legein e o teukhein. Esses termos designam operações orientadas por uma lógica identitária-conjuntista, isto é, por uma racionalidade que institui relações de valor, buscando pertencimento, semelhança e unidade entre elementos, com a finalidade de construir sentido. 
O legein tem no imaginário sua origem e seu destino ao instituir correlações entre objetos e significados, criando e nomeando formas, e definindo quais sentidos valem para elas. Trata-se de um processo social que envolve as operações conjugadas de diferenciar, juntar, escolher, nomear e determinar o que algo é - operações que criam sentidos ao compor conjuntos formados por objetos e suas significações, reunidos por similaridades convencionadas. A linguagem é uma das criações e também uma atividade social do legein, pelo fato de ser um sistema constituído por agrupamentos de fonemas e morfemas, de equivalências entre termos e significações, e de determinações de valor entre objetos e suas designações. As relações entre esses conjuntos constroem um magma de significações (CASTORIADIS, 1982, p. 277-278) com base no qual se elabora o dizer social. De acordo com Castoriadis (1982, p. 284-285), a designação, como determinação de significações, é a operação-chave do legein. Essa operação institui a identidade como elemento constituinte do imaginário social e o faz por meio da atribuição de valor a formas, figuras e imagens.

As atividades representativas do legein estão umbilicalmente associadas àquelas pertinentes ao teukhein, termo relativo ao fazer social e do qual se originou a palavra techné (CASTORIADIS, 1982, p. 301). Assim como o legein, o teukhein está implicado no imaginário, correspondendo à conjuntização do mundo por meio das operações de juntar, ajustar, fabricar e construir. Ao se realizarem, essas operações atribuem significações aos objetos, instituindo equivalências entre eles e as funções que Ihes são atribuídas. Para que essa determinação seja possível é preciso que o imaginário faça correlações de sentido, ou seja, que junte, diferencie, escolha e nomeie objetos, e atribua valor a eles. Isso significa que o legein é um teukhein pelo fato de o dizer social e o fazer social serem um espelho do outro. Como explica Castoriadis (1982, p. 301-302, grifos do autor),

O teukhein implica intrinsecamente o legein, é, em certo sentido, um legein porque ele opera e só pode ser distinguindo-escolhendo-juntando-estabelecendocontando. O teukhein separa "elementos", fixa-os como tais, os ordena, os combina, os reúne em totalidades e em hierarquias organizadas de totalidades no campo do fazer. [...] Inversamente, o legein implica intrinsecamente o teukhein, é, em certo sentido, um teukhein. Porque ele junta-ajusta-fabrica-constrói os elementos "materiais-abstratos" da linguagem bem como o conjunto de "objetos" e de "relações" que lhes corresponde. A fabricação da linguagem como código é um trabalho do teukhein; é um fazer ser... a partir de... de maneira apropriada a... e com vistas a... O legein não é legein se não é totalidade organizada de operações eficazes de suporte "material". O teukhein não é teukhein se não é colocação de elementos distintos e definidos, tomados em relações funcionais (tanto no sentido corrente como no sentido matemático da palavra função). (1982, p. 301-302, grifos do autor).

O dizer social e o fazer social são, assim, esquemas conjugados, de modo indestrinçável, que instituem interdependências entre instrumentos e significações. 
Na comunhão entre legein e teukhein, a técnica é atividade social (CASTORIADIS, 1982, p. 301-306) ou condensação do imaginário na imbricação do dizer e do fazer social. A técnica é social não tanto porque, para ser criada e reproduzida, dependa de relações entre seres humanos; mas porque é emergência, socialização e institucionalização de formas, em determinada sociedade e para ela, que não existiam antes. A técnica é, assim, uma configuração imaginária, até mesmo quando significada como autônoma ou um fim em si (CASTORIADIS, 1982, p. 305).

\section{Legein e teukhein configurados em redes sociotecnológicas}

No âmbito do imaginário, a ligação entre o dizer social e o fazer social é operada pela imanência de tempo-espaço - tempo na qualidade de emergência de alteridades que são configurações de espaço. Essas formas incorporam valores de época, ou são, elas próprias, valores encarnados, isto é, equivalências entre objetos (físicos ou abstratos) e significações, expressas em configurações determinadas por e para certa sociedade. No trabalho do imaginário, as formas são amálgamas do dizer social e do fazer social; são manifestações articuladas de modos de ver; de reunir e identificar semelhanças e diferenças; de julgar e atribuir valor a objetos, práticas, indivíduos e relações; de distinguir, escolher e estabelecer funções; de juntar, contar, ajustar, fabricar e construir.

A comunicação mediática situa-se nesse conjunto de atividades como uma das criações do imaginário instituinte. Crary (2012), quando escreve sobre o observador do século XIX, um sujeito envolvido com a produção de conhecimento científico, com sistemas de pensamento que buscaram racionalizar o corpo (percepção/subjetividade) e máquinas projetadas para produzir imagens técnicas está, mesmo que indiretamente, se referindo ao trabalho do imaginário instituinte de época, concretizado em práticas de produção de sentido, que instituíram a figura do observador no concurso de fatores conjunturais de determinada realidade social.

Nas situações apresentadas por Crary (2012), a câmara escura, o fenacistoscópio, o diorama, o caleidoscópio e o estereoscópio eram máquinas de produzir imagens técnicas, que simbolizavam o observador instituído como corpo racionalizado tal racionalização harmonizava-se com deslumbramento, curiosidade e divertimento com as máquinas e as imagens por elas produzidas. As máquinas em questão equivaliam a formas emergentes do ato de criação do imaginário radical (formante), desdobrado em formas socializadas (imaginário instituído) por meio do trabalho da psique, empenhado em gerar, compulsoriamente, representações. Estas se materializam de inúmeras maneiras, como linguagem, objetos técnicos, imagens e simbolizações generalizadas, institucionalizadas ou não. Castoriadis argumenta que o ato de pôr em formas, das quais as imagens correspondem apenas a um tipo, nada mais é do que o trabalho primordial da psique de "[...] dar figurabilidade ao que, por si só, não tem figura [para ela própria, 
a psique]" (CASTORIADIS, 1999, p. 267, grifo do autor). O que não tem figura é a pulsão, carga energética, de ordem somática, interpretada e organizada pela psique no ato, presidido por ela, de conferir existência a um "algo" (pulsão) na forma de representação (CASTORIADIS, 1999, p. 268). Essas representações constituem o elemento situado "entre" o fechamento da psique e sua abertura, obrigatória, ao outro, a quem é imputada a função de destino da pulsão.

No contexto dessa concepção do imaginário, o observador do século XIX construído por Crary (2012) vige como corpo (psique) comprometido com o predomínio do pensamento científico como sistema de poder (corpo e poder simbolizados como formas criadas pelo psiquismo humano) que buscava a objetivação e o controle de fenômenos subjetivos (CRARY, 2012, p. 71-99). O empreendimento do qual essas máquinas eram a protuberância consistia em buscar, obsessivamente, a precisão e a "verdade" da percepção e da imagem, concretizadas no desvelamento fisiológico do corpo e na criação de instrumentos e de imagens capazes de traduzir o que se acreditava ser a exatidão da forma, incluindo aí seu movimento. Tratava-se da construção de significações - no concurso entre técnica e subjetividade - do sujeito e do corpo nas funções de catalisadores do dizer social (significações) e do fazer social (técnica) de época.

As máquinas de produzir imagens técnicas - sua concepção, fabricação e disseminação como instrumentos que constituíam (e constituem ainda hoje) práticas sociais - participaram da instituição desse corpo matematizado e contribuíram para a possibilidade de objetivação do fenômeno da percepção como sistema físico-químico passível de ser nomeado, descrito e manipulado. As máquinas são, dessa maneira, agentes que compõem arranjos do dizer social e do fazer social e, nessa função, são elementos de processos do imaginário instituinte. As máquinas constituem cadeias de movimentos em dada sociedade, como parte dos processos de criação de significações; nesses processos, podem cumprir a função de mediadoras, no sentido atribuído ao termo por Deleuze (1995, p. 285), como algo que insere movimento em relações ou conecta elementos (objetos e/ou indivíduos) por meio do movimento, sendo esse o fator-chave para a criação de realidades sociais.

A mesma conjunção de legein e teukhein é exposta por Mannoni (2003) em sua reconstrução da história pré-cinematográfica. Essa história formou-se em processos de criação envolvendo conhecimento científico (óptica, geometria e fisiologia), práticas sociais que alinharam percepção, instrumentos e imagens, e imaginação fantástica. A concepção e o uso da câmara escura já na Idade Média (MANNONI, 2003, p. 31-34) reuniam conhecimentos sobre produção de imagens técnicas e pensamento religioso, com ele cumprindo a função de repertório sobre o oculto, os espíritos, a magia e a fantasmagoria, em suma, sobre o outro como aquele radicalmente desconhecido, em relação a quem se deve cultivar o temor, o riso, a repugnância ou o desejo.

$\mathrm{Na}$ modernidade, os instrumentos de produção de imagens somaram-se a outras criações técnicas, tais como os equipamentos empregados no campo (para lavrar a terra, 
extrair e beneficiar metais e minerais), os meios de transporte e as máquinas industriais (ASHTON, [1995]). O desenvolvimento dessa maquinaria colaborou para a formação, no século XIX, do que Kern (2003) denominou cultura do espaço e do tempo, que também poderia ser nomeada cultura da forma-movimento. O telégrafo, o cinematógrafo, o automóvel, o telefone, a rotativa para impressão de jornais, a bicicleta, a mecanização de processos produtivos e a locomotiva - invenções criadas na passagem do imaginário instituinte (radical) para o imaginário instituído (representações socialmente sancionadas) e que formaram o contexto estudado por Crary (2012) - expressaram o trabalho do imaginário social como criação de formas-significações do indivíduo e da sociedade, em uma época já animada pelo amadurecimento do modo capitalista de produção. O mesmo se pode dizer da invenção da televisão, que adensou processos de produção de sentido envolvendo conhecimentos em física, engenharia, química e matemática, interesses capitalistas (para a expansão comercial de equipamento e conteúdo, ambos sociais) e imaginação criadora sobre as relações entre sujeito, técnica e imagens.

Na esteira dessas invenções, as redes sociotecnológicas surgiram no final do século XX também como expressões da conjugação do dizer social com o fazer social, na medida em que o trabalho do imaginário radical é contínuo e recombina elementos para transformá-los em novas significações para dada sociedade. No processo social-histórico de criação de formas, os objetos técnicos são reelaborados e desdobrados, de modo não linear, em redes sociotecnológicas como herdeiras de desejos de sociabilidade e de representação do prazer, pela psique, na forma de objetos visuais (imagens) e relacionais.

A configuração originária de tais redes foi identificada por boyd e Ellison (2008, p. 214) no SixDegrees.com, primeiro site de serviços lançado em 1997, que permitia aos usuários criar perfis, listar amigos e consultar essa lista. Embora seja necessário considerar relativa diversidade em motivações, funcionalidades e usos desses serviços tecnológicos, eles têm em comum possibilitar conexões entre pessoas (e entre estas e empresas e instituições) e conferir a elas visibilidade. Na atualidade, essas finalidades não dependem apenas da ação humana, porque são fomentadas por algoritmos (BUCHER, 2015). Esse fato pode sugerir a autonomização do funcional na sociabilidade, porém também sinaliza a existência do algoritmo como objeto criado pela psique para lhe servir de suporte ou de representação do prazer em determinada forma.

A constituição dessas redes expressa a articulação de legein e teukhein como dimensões do imaginário instituinte, cristalizadas na ligação entre sujeito, outrem e instrumentos tecnológicos. O primeiro e o segundo organizam-se em redes, como grupos que se formam orientados por afinidades temáticas, por relações familiares, de amizade ou profissionais, estabelecidas nas próprias redes sociotecnológicas ou em relações presenciais. Trata-se de relações de identificação ou de conexões que formam conjuntos ou grupos (de indivíduos, ideias, necessidades e desejos). Os terceiros são projetados e fabricados (imaginados, esquematizados e construídos) para promover tal 
organização ("nascem" sociais) e, para isso, são concebidos com funcionalidades alinhadas às possibilidades de experiência situadas na lógica identitária-conjuntista. Por essas razões, as referidas redes são nomeadas aqui "sociotecnológicas", na tentativa de expressar uma realidade que, ao ser tecnológica, é social, embora esses termos possam ser interpretados como redundantes, assim como o nome "rede social" também o é.

Em sentido positivo, a lógica identitária-conjuntista, em operação nessas redes, manifesta-se, concretamente, ao modo de relações de amizade, solidariedade e coleguismo, que se juntam à própria vocação social da arquitetura tecnológica que lhes oferece suporte. Até mesmo as relações fortuitas, provocadas por conexões ocasionais entre indivíduos interessados em compartilhar ou trocar ideias, informações ou opiniões, podem ser qualificadas como identitárias-conjuntistas. Nas bordas dessa lógica cabem ainda relações que aglutinam contrários - indivíduos com interesse em um mesmo objeto, porém, com pontos de vista opostos sobre ele, com intenções antagônicas, sentimentos divergentes, e que se expressam uns para os outros, quanto ao objeto que lhes é comum, de maneira discordante e até agressiva. O que se pretende notar aqui é a vigência de uma força de reunião entre sujeito e outrem, latente na função da tecnologia empregada nas redes sociotecnológicas, a saber, a conexão e visibilidade entre indivíduos, empresas e instituições. Vale reafirmar que a tecnologia é ela própria expressão do social, e este, do ponto de vista intersubjetivo, é uma necessidade da psique para elaborar suas demandas. Isso faz das conexões a condição sociotecnológica fundamental na significação do sujeito na atualidade, ao menos daquele que se compreende participante de uma realidade que não é outra senão aquela urdida com participação inelidível dos media e da tecnologia de comunicação.

As conexões como funcionalidade de base das redes sociotecnológicas são o expoente da transformação da sociabilidade em negócio; foram concebidas como meio para obtenção de resultados financeiros por parte de empresas que nasceram para atuar nesse nicho de mercado. A sociabilidade tornou-se, assim, um serviço pelo qual imaterialmente se paga ativando conexões e promovendo a visibilidade de si e de outrem. Nessas redes, o capital social dos agentes das conexões coincide com o capital social da tecnologia e das empresas deste setor.

As conexões são também criações sociotecnológicas impregnadas de imaginação sobre o reconhecimento intersubjetivo, equiparado à consideração de outrem como demanda válida ao significarem a potência de visibilidade do sujeito na sociabilidade. A visibilidade é condição de partida para a elaboração do desejo de ser desejado [conforme perspectiva da psicanálise lacaniana sobre o reconhecimento (LACAN, 1998, p. 269)] e para a constituição de si como destino de alguma atenção. Assumida como valor incrustado nas conexões, a visibilidade faz o reconhecimento estar disponível para ser simbolizado na relação entre sujeito, outrem e funcionalidades do ambiente tecnológico, independentemente da forma como a significação dessa experiência é assumida, expressa e assimilada. O reconhecimento, expulso de seu sentido canônico na teoria social - que 
o enuncia como o ato político de aceitar outrem como fonte de pretensões legítimas, a quem se deve, portanto, respeito (HONNETH, 2011, p. 165-181) -, é a palavra-chave das redes sociotecnológicas ao reforçar o sentido intersubjetivo das conexões. Nesse ambiente heterogêneo, que combina o social, o econômico (tecnologia inclusa), o político (porque participa de relações de poder) e o cultural, o reconhecimento tornouse experiência processada no fluxo do capital.

A reunião entre subjetividade e tecnologia comparece na história das redes sociotecnológicas não apenas porque esses empreendimentos sociais se constituíram privilegiando funcionalidades que correspondessem à sociabilidade como necessidade de sujeito e outrem, como se essas redes fossem um fato autônomo e tecnológico no sentido estrito e técnico do termo. As redes sociotecnológicas, traduzidas na tríade tecnologiaconexão-visibilidade, são expressões do dizer social e do fazer social, indispensáveis para a urdidura do que Boltanski e Chiapello (2009, p. 39-52) denominaram terceiro espírito do capitalismo - a ideologia que justifica o engajamento da subjetividade no capitalismo em sua fase atual, de natureza tecnológica. A conectividade é qualidade sine qua non do sujeito dessa fase do capitalismo, sendo o corpo o "ambiente" de significação do teukhein, necessário para a conservação do sistema capitalista de produção.

Boltanki e Chiapello (2009, p. 84) observam que o espírito do capitalismo “[...] apresenta duas faces, uma voltada para a acumulação de capital e a outra, para princípios de legitimação [...]". Para prosperar e firmar-se como realidade inquestionável, tal sistema ideológico precisa concretizar-se na ligação entre instrumentos e significações, ambos socialmente assimilados como legítimos, pois sustentados por justificações. As funções instrumentais e de sentido do capitalismo tecnológico foram captadas pelos autores na literatura de gestão empresarial dos anos 1990. Essa literatura referia-se a métodos para obtenção de lucros, estratégias para competição, procedimentos para a gestão de equipes e pregava valores que prescreviam a empresa ideal (BOLTANSKI; CHIAPELLO, 2009, p. 84), expressando, assim, a ideologia de época que instituía um novo modo de produtividade do corpo.

A contrapartida da forma tecnológica assumida pelo capital para processar e representar sua operação espaçotemporal encontra-se, desde então, não apenas em expressões instrumentais, cristalizadas em variedades de hardware e software vocacionados ao processamento de informação e comunicação, mas também em práticas sociais correspondentes à socialização desses objetos; eles são concebidos com a sociabilidade já "embarcada".

Os objetos sociotecnológicos engendrados pelo projeto do terceiro espírito do capitalismo - ele mesmo criação do imaginário instituinte - são elementos ativos no engajamento social, necessário para fazer prosperar um sistema de ideias espelhado em modalidades sociais, econômicas e culturais de produtividade, que se tornam possíveis na cooperação entre corpo e objeto. Os instrumentos técnicos e tecnológicos são, portanto, 
constituintes de relações intersubjetivas, confundem-se com elas, pelo fato de serem assumidos como significantes com os quais o sujeito se elabora. Trata-se de uma operação intrincada de produção de sentido, que transpassa as relações intersubjetivas aglutinadas em redes simbólicas (CASTORIADIS, 1982, p. 159) intercomunicantes, tais como a empresa, a família, a entidade religiosa, a instituição de ensino, a universidade (criadora e reprodutora de significações e de instrumentos assimilados pela sociedade) e os media.

A ampla circulação de significações do capitalismo tecnológico, socialmente legitimadas, colaborou para a construção de um modo de vida em rede, indistinto de um modelo de produtividade do corpo/da subjetividade, com o termo rede associado à expressão de um sujeito específico (BOLTANSKI; CHIAPELLO, 2009, p. 102-103). A metáfora da "rede" concilia subjetividade (o dizer social) e instrumentos (o fazer social) de época, projetados, na esteira do desenvolvimento da informática, para viabilizar o sujeito conectado, disponível, móvel e flexível.

O imaginário que institui esse sujeito, necessariamente investido do tempo tecnológico como coordenada fundamental do terceiro espírito do capitalismo, institui também a modalidade correlata do tempo sociotecnológico. A expressão e percepção dessa modalidade de tempo vêm sendo remontadas desde os processos do imaginário que resultaram no aparecimento do telégrafo, do rádio, do cinema e da televisão como aglutinações de formas projetadas pela psique, assentadas em conhecimento científico, cultura, capitalismo e incorporação de sua lógica pelo social. Com base nos argumentos de Castoriadis (1982, p. 246-252), é possível afirmar que o espaço-tempo imaginário se põe em condensações (formas) do dizer social (legein) e do fazer social (teukhein), entre as quais estão as redes sociotecnológicas, uma arquitetura criada, nas condições expostas, pelo imaginário instituinte que gesta o corpo válido para uma época e os instrumentos pertencentes a ele.

Angela Pintor dos Reis é professora no Centro Universitário Senac. É doutora em Comunicação e Semiótica pela PUCSP e atualmente desenvolve pesquisa de pós-doutorado no Programa de Meios e Processos Audiovisuais, Departamento de Cinema, Rádio e Televisão, da ECA-USP.

angelapintor@terra.com.br

\section{Referências}

ASHTON, T. S. A revolução industrial. Mem Martins/Lisboa: Publicações Europa-América, [1995]. (Colecção Saber).

BOLTANSKI, L.; CHIAPELLO, È. O novo espírito do capitalismo. São Paulo: WMF Martins Fontes, 2009. 
BOYD, D.; ELISSON, N. Social network sites: definition, history and scholarship. Journal of ComputerMediated Communication, [s. I.], v. 13, n. 1, out. 2008. Disponível em: <http://onlinelibrary.wiley. com/doi/10.1111/j.1083-6101.2007.00393.x/full>. Acesso em: 14 out. 2015.

BUCHER, T. Networking, or what the social means in social media. Social Media + Society, abr.-jun. 2015, v. 1, n. 1. Disponível em: <http://journals.sagepub.com/doi/pdf/10.1177/2056305115578138>. Acesso em: 20 mar. 2018.

CASTORIADIS, C. A instituição imaginária da sociedade. Rio de Janeiro: Paz e Terra, 1982.

Socialismo ou barbárie: o conteúdo do socialismo. São Paulo: Brasiliense, 1983.

Feito e a ser feito: as encruzilhadas do labirinto V. Rio de Janeiro: DP\&A, 1999.

Figuras do pensável. Rio de Janeiro: Civilização Brasileira, 2004.

Uma sociedade à deriva: entrevistas e debates - 1974-1997. Aparecida: Ideias e Letras, 2006.

CRARY, J. Técnicas do observador: visão e modernidade no século XIX. Rio de janeiro: Contraponto, 2012.

DELEUZE, G. Mediators. In: CRARY, J. et. al. Zone. Nova lorque: MIT Press, 1995.

HONNETH, A. La sociedad del desprecio. Madri: Trotta, 2011.

KERN, S. The culture of time and space 1880-1918. Cambridge: Harvard University Press, 2003.

KLOOGER, J. Ensemblistic-identitary logic (ensidic logic). In: ADAMS, S. Cornelius Castoriadis: key concepts. Londres: Bloomsbury Academic, 2014.

LACAN, J. Escritos. Rio de Janeiro: Jorge Zahar, 1998.

MANNONI, L. A grande arte da luz e da sombra: arqueologia do cinema. São Paulo: SENAC São Paulo; UNESP, 2003. 